\title{
High-throughput virtual screening for a new class of antagonist targeting LasR of Pseudomonas aeruginosa
}

Aishwarya Vetrivel $^{a}$, Santhi Natchimuthu ${ }^{a}$, Vidyalakshmi Subramanian ${ }^{b}$, Rajeswari Murugesan ${ }^{\text {* }}$

a Department of Biochemistry, Biotechnology and Bioinformatics, Avinashilingam Institute for Home Science and Higher Education for Women, Coimbatore-641043, Tamil Nadu, India.

b Department of Biotechnology, PSG College of Technology, Coimbatore-641004, Tamil Nadu, India.

\section{"Corresponding author:}

Dr. Rajeswari Murugesan,

Assistant Professor,

Department of Biochemistry, Biotechnology and Bioinformatics,

Avinashilingam Institute for Home Science and Higher Education for Women, Coimbatore-641043, Tamil Nadu, India.

E-mail: rajeshwari bc@avinuty.ac.in 
Table S1. Molecular docking analysis of known antagonists with LasR (3IX4) protein

\begin{tabular}{|c|c|c|c|c|c|}
\hline Antagonist & $\begin{array}{l}\text { pIC50 } \\
\text { value }\end{array}$ & $\begin{array}{l}\text { Docking score } \\
\text { (kcal/mol) }\end{array}$ & $\begin{array}{c}\text { Glide } \\
\text { energy }\end{array}$ & $\begin{array}{l}\text { H-bond interaction } \\
\text { residues }\end{array}$ & References \\
\hline & 5.9 & -11.15 & -62.66 & $\begin{array}{c}\text { Tyr47, Tyr56, Trp60, } \\
\text { Asp73, Ser129 } \\
\end{array}$ & \multirow{4}{*}{$\begin{array}{c}\text { Geske et al., } \\
2008^{36}\end{array}$} \\
\hline & 5.0 & -10.18 & -62.90 & $\begin{array}{c}\text { Tyr56, Asp73, Tyr93, } \\
\text { Ser129 }\end{array}$ & \\
\hline 血 & 5.6 & -9.48 & -58.47 & $\begin{array}{c}\text { Tyr56, Trp60, Asp73, } \\
\text { Ser129 }\end{array}$ & \\
\hline 8 & 7.0 & -9.45 & -49.51 & Tyr56, Ser129 & \\
\hline & 5.3 & -9.45 & -68.44 & Tyr47, Arg61, Tyr93 & $\begin{array}{c}\text { O'Brien et al., } \\
2014^{37}\end{array}$ \\
\hline & 6.5 & -9.45 & -50.91 & Tyr56, Asp73, Ser129 & $\begin{array}{l}\text { Choi et } \\
\text { al.,201738 }\end{array}$ \\
\hline & 4.0 & -9.18 & -69.21 & Tyr56, Asp73, Ser129 & \multirow[b]{2}{*}{$\begin{array}{l}\text { O'Reilly et al. } \\
2018^{39}\end{array}$} \\
\hline 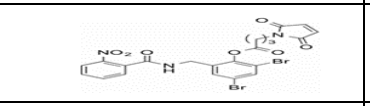 & 6.0 & -9.07 & -56.76 & Tyr56, Asp73, Ser129 & \\
\hline & 5.7 & -8.64 & -58.21 & $\begin{array}{c}\text { Arg61, Trp60, Tyr56, } \\
\text { Asp73, Ser129 }\end{array}$ & $\begin{array}{l}\text { Smith et al., } \\
2003^{40}\end{array}$ \\
\hline & 4.0 & -8.62 & -60.42 & Asp73, Ser129 & \multirow{20}{*}{$\begin{array}{l}\text { Ni et al., } \\
2008^{41}\end{array}$} \\
\hline S & 4.0 & -8.51 & -64.73 & Thr75, Ser129 & \\
\hline S & 4.0 & -8.43 & -67.25 & Arg61 & \\
\hline & 5.6 & -8.39 & -65.12 & Thyr56, Ser129 & \\
\hline & 5.2 & -8.39 & -66.99 & Arg61, Tyr47, Tyr93 & \\
\hline & 5.6 & -8.28 & -62.64 & Tyr56, Asp73, Ser129 & \\
\hline & 4.0 & -7.96 & -69.86 & Tyr56, Asp73, Ser129 & \\
\hline & 5.6 & -7.94 & -59.84 & Val76, Ser129 & \\
\hline & 5.3 & -7.93 & -68.20 & Val56, Asp73, Ser129 & \\
\hline- & 4.3 & -7.87 & -52.71 & Asp73, Tyr56, Ser129 & \\
\hline OI & 4.3 & -7.71 & -69.79 & $\begin{array}{c}\text { Trp60, Tyr56, Asp73, } \\
\text { Ser129 }\end{array}$ & \\
\hline & 4.3 & -7.65 & -59.88 & Tyr56, Asp73, Ser129 & \\
\hline & 5.8 & -7.56 & -63.91 & Tyr56, Ser129 & \\
\hline & 5.4 & -7.59 & -59.74 & Arg61 & \\
\hline$\sim$ & 5.3 & -7.45 & -59.20 & Tyr56, Ser129 & \\
\hline wi & 6.04 & -7.45 & -69.92 & Arg61, Tyr47, Tyr93 & \\
\hline$m$ & 6.0 & -7.44 & -58.03 & Tyr56, Asp73, Ser129 & \\
\hline miro & 5.9 & -7.42 & -62.77 & Tyr56, Asp73, Ser129 & \\
\hline थर & 6.2 & -7.41 & -49.25 & Val76, Ser129 & \\
\hline & 5.7 & -7.36 & -67.81 & Val56, Asp73, Ser129 & \\
\hline miris & 6.2 & -7.34 & -55.91 & Asp73, Tyr56, Ser129 & \multirow{4}{*}{$\begin{array}{l}\text { Smith et al., } \\
2003^{40}\end{array}$} \\
\hline$\sim r^{\prime \prime} R^{2}$ & 5.3 & -7.34 & -57.03 & $\begin{array}{c}\text { Asp73, Arg61, Tyr56, } \\
\text { Ser129 }\end{array}$ & \\
\hline milse & 8.0 & -7.19 & -41.36 & Tyr56 & \\
\hline mirgr & 9.0 & -7.13 & -30.12 & Tyr56, Trp60, Asp73, & \\
\hline
\end{tabular}




\begin{tabular}{|c|c|c|c|c|}
\hline & & & & Ser129 \\
\hline minin & 6.4 & -7.07 & -69.19 & Tyr56, Trp60, Asp73 \\
\hline mino & 6.08 & -7.02 & -60.14 & Thr75, Ser129 \\
\hline miis & 4.2 & -6.91 & -66.90 & $\begin{array}{c}\text { Trp60, Tyr56, Asp 73, } \\
\text { Ser129 }\end{array}$ \\
\hline
\end{tabular}

